\title{
Tecnologias digitais e o fenômeno da superdotação: uma análise do conhecimento de estudantes e professores da educação básica
}

\author{
Ketilin Mayra Pedro* \\ Vera Lúcia Messias Fialho Capellini**
}

\begin{abstract}
Resumo
O objetivo deste artigo consistiu na análise do conhecimento de estudantes com superdotação, e de seus respectivos professores, no que se refere à utilização das Tecnologias Digitais da Informação e Comunicação (TDIC). Trata-se de uma pesquisa descritiva que foi desenvolvida no Projeto de Extensão "Identificação de estudantes com habilidades superiores e aconselhamento para pais e equipe escolar". Como instrumentos de pesquisa foram aplicadas atividades do Programa de Atividades Dirigidas (PEDRO, 2016). Foram também utilizados dois questionários elaborados no Google Forms. A análise do desempenho dos estudantes revelou que, embora eles sejam considerados nativos digitais, há a necessidade de aperfeiçoar o modo como esses realizam pesquisas e utilizam ferramentas de produção. Sobre o conhecimento dos professores, verificou-se que ainda há uma subutilização dos recursos tecnológicos no âmbito escolar, visto que os professores exploram com mais frequência recursos como vídeos e filmes, em detrimento dos recursos que possibilitam maior interação e produção de conteúdos. Nesse sentido, faz-se necessário ofertar aos professores uma formação que vá ao encontro das suas necessidades para que eles possam disponibilizar atividades pedagógicas, por meio das TDIC, que possibilitem aos estudantes a utilização de ferramentas de produção, bem como a capacidade de efetuar a avaliação crítica das informações disponíveis na internet.
\end{abstract}

Palavras-Chave: tecnologias digitais da informação e comunicação, superdotação, educação básica, competências digitais.

Digital technologies and the giftedness phenomenon: an analysis of the knowledge of basic education students and teachers

Abstract

This article aimed to analyze the knowledge of gifted students and their respective teachers regarding the use of Digital Information and Communication Technologies (DICT). It is a descriptive study developed in the Extension Project called "Identificação de estudantes com habilidades superiores e aconselhamento para pais e equipe escolar" (Identification of students with higher skills and counseling for their parents and school staff). The instruments applied were activities of the Programa de Atividades Dirigidas (PEDRO, 2016) and two questionnaires created in the Google Forms. The analysis of the students' performance showed that although they are considered digital natives, there is a need to improve the way they conduct research and use production tools. Regarding the teachers' knowledge, it was verified that technological resources are still underutilized in the school environment since teachers more often exploit resources such as videos and films to the detriment of resources that allow a greater interaction and content production. In this regard, it is necessary to provide teachers with training that meets their needs, so that they can offer their students some pedagogical activities, through the DICT, which enable the student to use production tools and critically evaluate information available on the internet.

Keywords: digital information and communication technologies, giftedness, basic education, digital skills.

\footnotetext{
* Doutora em Educação. Centro Universitário Sagrado Coração - Bauru/SP. E-mail: ketilinp@yahoo.com.br.

*** Doutora em Educação. Universidade Estadual Paulista Julio de Mesquita Filho - Campus Bauru. E-mail: vera.capellini@unesp.br.
} 


\section{Introdução}

A literatura, nacional e internacional, apresenta variadas definições e características sobre o fenômeno da superdotação. O teórico norte-americano Joseph $\mathrm{S}$. Renzulli caracteriza os estudantes com altas habilidades/superdotação (AH/SD) como aqueles que apresentam três traços humanos: habilidade acima da média, envolvimento com a tarefa e altos níveis de criatividade.

A manifestação da superdotação pode ser classificada em dois tipos, o primeiro tipo é a superdotação escolar ou acadêmica, a qual é associada aos estudantes que exibem boa pontuação em testes de inteligência e também obtêm boas notas na escola; esses estudantes são percebidos mais facilmente dentro do ambiente escolar e geralmente são identificados e encaminhados para serviços e programas de atendimento. O segundo tipo é a superdotação criativo-produtiva, caracterizada pelo desenvolvimento de ideias, produtos e expressões artísticas originais (RENZULLI, 2014).

$\mathrm{O}$ atendimento educacional ao estudante com AH/SD pode ocorrer de variadas maneiras: flexibilização curricular, alterações nos objetivos e nas metodologias das atividades pedagógicas, programas de desenvolvimento pessoal do sujeito, aceleração e enriquecimento (FREITAS; PÉREZ, 2010).

Sobre os recursos que podem ser utilizados na realização das atividades, alguns teóricos (SHAMBLIN, 2011; HUNG et al. 2012) apontam que as Tecnologias Digitais da Informação e Comunicação (TDIC) configuram-se como ferramentas de enriquecimento intelectual que podem potencializar o desenvolvimento de todos os estudantes, inclusive daqueles que apresentam habilidades acima da média.

Para Renzulli (2014, p. 224), o conhecimento está se disseminando em proporções quase geométricas, sendo "sábio considerar um modelo que enfocasse como nossos alunos mais hábeis acessam e usam a informação, em vez de enfocar meramente como eles a acumulam e estocam".

Considerando os apontamentos de Renzulli (2014) e o cenário atual referente à cultura digital e à Sociedade da Informação, desenvolveu-se o estudo de Pedro (2016) com o objetivo de comparar estudantes nativos digitais que apresentavam AH/SD com nativos digitais não identificados como tais, no uso das TDIC. Observou-se nesse estudo que, embora as habilidades e competências digitais dos estudantes de ambos os grupos 
sejam semelhantes, aqueles que apresentavam AH/SD demonstravam mais qualidade nas ações executadas.

Tendo por base os resultados do referido estudo sobre a necessidade de desenvolver competências digitais em estudantes com AH/SD para que eles possam utilizar as TDIC enquanto recurso de enriquecimento intelectual, identifica-se a necessidade de refletir sobre a capacitação dos professores em relação à utilização das TDIC em sala de aula, uma vez que eles atuam cotidianamente com os estudantes e compartilham da responsabilidade de torná-los digitalmente competentes.

Diante do exposto, o objetivo geral deste artigo consistiu na replicação dos instrumentos utilizados no estudo de Pedro (2016) e na análise do conhecimento dos professores em relação à utilização educacional das TDIC.

\section{Método}

Trata-se de uma pesquisa descritiva que foi desenvolvida no Projeto de Extensão "Identificação de estudantes com habilidades superiores e aconselhamento para pais e equipe escolar", da Faculdade de Ciências da Universidade Estadual Paulista - Campus Bauru. Participaram dessa pesquisa seis estudantes identificados com superdotação acadêmica (RENZULLI, 2014) e seus respectivos professores. Quanto aos procedimentos éticos, o presente projeto de pesquisa foi aprovado no Comitê de Ética pelo parecer de número 1.817.954.

Contataram-se inicialmente os pais e/ou responsáveis dos estudantes participantes do projeto de extensão, com o intuito de apresentar a presente pesquisa e solicitar o aceite para a sua realização.

Após o consentimento dos pais, agendaram-se as datas em que os dados seriam coletados, sendo que foi utilizado o espaço do projeto de extensão para a aplicação dos instrumentos. Após a seleção e contato inicial com os estudantes da pesquisa, as respectivas instituições de ensino em que eles se encontravam matriculados foram visitadas, a fim de convidar seus professores para também participarem da pesquisa. Obtivemos o aceite de apenas um professor de cada escola, sendo que um professor de cada estudante participou da pesquisa. O Quadro 1 apresenta informações sobre a faixa etária e ano escolar dos estudantes participantes. 
Quadro 1 - Caracterização dos estudantes

\begin{tabular}{|c|c|c|}
\hline Identificação & $\begin{array}{c}\begin{array}{c}\text { Idade } \\
\text { (em anos) }\end{array} \\
\end{array}$ & Informações Escolares \\
\hline Alice & 11 & $6^{\circ}$ ano - Escola Estadual \\
\hline Eduarda & 11 & $6^{\circ}$ ano - Escola Estadual \\
\hline Gustavo & 14 & $7^{\circ}$ ano - Escola Estadual \\
\hline Luis & 9 & $4^{\circ}$ ano - Escola Estadual \\
\hline Maria Fernanda & 9 & $4^{\circ}$ ano - Escola Estadual \\
\hline Vitor & 10 & $6^{\circ}$ ano - Escola Particular \\
\hline
\end{tabular}

Fonte: Elaboração própria.

Sobre a caracterização dos professores participantes, verificou-se que quatro deles indicaram possuir vasta experiência docente, sendo essa em torno de 20 a 30 anos. Um indicou ter de 10 a 15 anos de experiência e outro de 15 a 20 anos. Todos os professores indicaram atuar na rede pública de ensino, sendo que dois deles também atuavam na rede particular. Em relação à faixa etária, verificamos que três estavam na faixa de 46 a 55 anos, dois na faixa dos 36 a 45 anos e um de 26 a 35 anos.

Com o objetivo de investigar como os participantes usavam as TDIC foram replicadas algumas das atividades do Programa de Atividades Dirigidas (PEDRO, 2016), nas quais foi possível observar o modo como os participantes buscavam e selecionavam informações, por meio da internet, e como interagiam com sites e jogos variados. Além desse instrumento, foram elaborados dois formulários online, por meio do Google Forms. O primeiro destinava-se aos estudantes e versava sobre os tipos e a frequência com que eles utilizavam os recursos tecnológicos. O segundo foi direcionado aos professores com o objetivo de identificar os conhecimentos que eles têm sobre a utilização das TDIC no contexto educacional.

Os dados foram explicitados de maneira descritiva, quantificados e analisados qualitativamente. Destaca-se, uma vez mais, que o desempenho dos estudantes no instrumento foi analisado de acordo com os estudos de Pedro (2016), sendo que o desempenho de cada estudante foi classificado em três categorias: 1- Desconhecimento tem certa familiaridade com o computador, mas ainda não realiza independentemente a maioria das atividades; 2- Tentativa e erro - explora os recursos de maneira aleatória e não possui um rumo pré-determinado, fazendo com que as dificuldades se transformem em aprendizado; 3- Consciente - passa pela experiência do aprendizado e possui 
familiaridade com os ambientes informacionais, tornando suas ações mais orientadas e seguras, na medida em que recebe poucos esclarecimentos.

Os demais dados foram agrupados e analisados com base no referencial teórico da área da superdotação e da tecnologia educacional.

\section{Resultados e Discussões}

Sobre a utilização de computadores e smartphones, a maioria dos estudantes indicou fazer uso dos referidos recursos constantemente, sendo que cinco estudantes utilizavam o computador todos os dias, um utilizava de duas a três vezes na semana, quatro utilizavam o smartphone a todo o momento, enquanto dois afirmaram utilizar apenas quando precisavam enviar mensagem para familiares ou amigos. Utilizar as TDIC de modo constante é uma das características dos estudantes nascidos na era digital. De acordo com a literatura, as TDIC configuram-se como extensões do nosso próprio corpo, sendo que a mobilidade proporcionada pelos equipamentos portáteis possibilita o acesso à internet a todo o momento e em qualquer lugar (SANTAELLA, 2014).

Em relação às atividades que os estudantes mais costumavam realizar por meio das TDIC, identificou-se que a utilização de aplicativos de mensagens como WhatsApp, acesso às redes sociais, assistir vídeos no Youtube e utilizar jogos online configuram-se como as atividades preferidas dos estudantes participantes. Pode-se apontar que tais atividades são preferidas por conta da interatividade e dinamismo proporcionados por esses recursos, sendo que estudantes nascidos na era digital apresentam preferência por conteúdos imagéticos e dinâmicos (MONEREO, 2010; ANSELL, 2016).

Sobre a segurança digital, os estudantes são cautelosos na utilização das TDIC, uma vez que todos os estudantes não acessavam conteúdos inapropriados para a idade, cinco não adicionavam pessoas desconhecidas nas redes sociais e quatro afirmaram que os pais supervisionavam o uso das tecnologias. Embora a segurança seja uma das competências digitais, não é comum encontrar estudantes que tenham ciência dos cuidados necessários, os participantes da pesquisa, no entanto, destacaram-se ao revelar que são cuidadosos, principalmente em relação ao uso das redes sociais, demonstrando apresentar competências na área da segurança digital (MONEREO, 2010). 
Apresenta-se a seguir o desempenho dos estudantes nas atividades propostas por meio de quadros, sendo que a classificação do desempenho em cada atividade está indicada pelo número apresentado em parênteses.

Quadro 2 - Atividade: Pacote Office

\begin{tabular}{|l|l|}
\hline \multicolumn{2}{|c|}{ Atividades - Pacote Office } \\
\hline Maria Fernanda & $\begin{array}{l}\text { Precisou de esclarecimento e ajuda para acessar o Microsoft Office Word. Digitou } \\
\text { o próprio nome, no entanto precisou de esclarecimento e ajuda para a realização da } \\
\text { formatação (1). }\end{array}$ \\
\hline Gustavo & $\begin{array}{l}\text { Não teve dificuldade para acessar o software, entretanto, não conhece as funções } \\
\text { básicas. No Word digitou o próprio nome e precisou de esclarecimento para fazer a } \\
\text { formatação (não fazia a seleção), soube inserir uma figura, no entanto não soube } \\
\text { formatar adequadamente. No Excel e no PowerPoint realizou ações básicas com } \\
\text { esclarecimento e ajuda (2). }\end{array}$ \\
\hline Vitor & $\begin{array}{l}\text { Precisou de esclarecimento e ajuda para abrir o Microsoft Office Word, para } \\
\text { formatar o texto, colocar a figura e salvar o arquivo. Não realizou as demais } \\
\text { atividades e não explorou o Excel e o PowerPoint (2). }\end{array}$ \\
\hline Eduarda & $\begin{array}{l}\text { Precisou de ajuda para abrir o Microsoft Office Word, explorou os recursos de } \\
\text { maneira aleatória (tentativa e erro). Sabe utilizar a paleta de cores, contudo, não } \\
\text { demonstra muita habilidade na utilização, precisou de bastante tempo para realizar } \\
\text { as ações. Precisou de ajuda e esclarecimento para copiar e colar a figura e salvar o o } \\
\text { arquivo. Não soube utilizar o Excel e o PowerPoint (2). }\end{array}$ \\
\hline Alice & $\begin{array}{l}\text { Precisou de ajuda e esclarecimento para abrir o software, realizar a formatação, } \\
\text { copiar e colar uma figura da internet e salvar o arquivo. (1) }\end{array}$ \\
\hline Luís & $\begin{array}{l}\text { Realizou todas as atividades, o estudante explorou as ferramentas até encontrar } \\
\text { aquilo que procurava, precisou de ajuda apenas para salvar o documento (2). }\end{array}$ \\
\hline
\end{tabular}

Fonte: Elaboração própria.

A maioria das ações solicitadas durante a efetivação dessa atividade era executada por meio de ferramentas representadas por ícones; nota-se que os estudantes memorizavam a imagem e, muitas vezes, desconheciam o nome da ferramenta ou sua real função, evidenciando que os estudantes considerados nativos digitais estão acostumados e preferem uma linguagem icônica (PALFREY; GASSER, 2011), a qual favorece a exploração das TDIC de modo rápido e significativo.

Illera e Roig (2010) fazem uma relação entre a linguagem icônica e os impactos que os recursos digitais têm na leitura e na escrita. Esses autores apontam que, antes da disseminação das TDIC, somente as pessoas alfabetizadas eram capazes de utilizar essas tecnologias e que, com a inovação tecnológica dos últimos anos, esse emprego foi ampliado para aqueles que ainda não dominam tais habilidades. A referida mudança é impulsionada pelo setor de informática, que cada vez mais tem criado interfaces simples e imagéticas, facilitando a manipulação desses dispositivos através dos ícones. 
Observa-se também que os estudantes possuíam maior familiaridade com as ferramentas do Microsoft Office Word, sendo que os demais aplicativos do Pacote Office não apresentavam muita funcionalidade para eles. Tal realidade pode estar relacionada com o fato da maioria dos estudantes utilizarem o referido programa para a realização de atividades e trabalhos escolares, enquanto os demais aplicativos ainda não são explorados na educação básica do modo como deveriam, uma vez que a utilização dos recursos tecnológicos no contexto escolar ainda se restringe à realização de pesquisas escolares e enquanto ferramenta de entretenimento (RIVERO, 2004).

Quadro 3 - Atividade: Pesquisa na internet

\begin{tabular}{|l|l|}
\hline \multicolumn{2}{|c|}{ Atividade - Pesquisa na internet } \\
\hline Maria Fernanda & $\begin{array}{l}\text { Não soube acessar o navegador, precisou de ajuda e esclarecimento. Fez uma pesquisa } \\
\text { por "Animais no Pantanal", relatou que costuma ler o título do site e a descrição que } \\
\text { segue abaixo para verificar qual é o mais completo (3). }\end{array}$ \\
\hline Gustavo & $\begin{array}{l}\text { Acessou o Google e fez uma pesquisa sobre "radioatividade", costuma escrever } \\
\text { exatamente aquilo que procura (frases longas). Acessa sempre a Wikipédia, pois } \\
\text { considera o site mais completo de todos. Se não encontra tudo o que procura acessa } \\
\text { outros sites (2). }\end{array}$ \\
\hline Vitor & $\begin{array}{l}\text { Acessou o Google Chrome sem dificuldades, utilizou a seguinte frase para realizar a } \\
\text { pesquisa "Quais são as características do período neolítico e paleolítico?". O aluno } \\
\text { relatou que observa o título e a descrição dos resultados, observa também se o } \\
\text { navegador indica se o site é seguro. O aluno acessou o Yahoo Respostas, mas mostrou } \\
\text { desconfiança sobre a confiabilidade do site (2). }\end{array}$ \\
\hline Eduarda & $\begin{array}{l}\text { Fez uma pesquisa na internet sobre "Menina de 5 anos grava fada". A aluna relatou } \\
\text { que abre vários sites até encontrar aquilo que precisa. Precisou de ajuda e } \\
\text { esclarecimento para copiar e colar o texto no Word (2). }\end{array}$ \\
\hline Alice & $\begin{array}{l}\text { Não precisou de ajuda para acessar o navegador, fez uma busca por "Flores Coloridas", } \\
\text { relatou ler o título do site para verificar qual parece ser o mais adequado. Precisou de } \\
\text { ajuda e esclarecimento para copiar e colar o conteúdo no Word (2). }\end{array}$ \\
\hline Luís & $\begin{array}{l}\text { Acessou o navegador sem dificuldades, fez uma pesquisa por "Como é feito o olho". } \\
\text { Relatou que costuma ler os resumos abaixo do link para considerar aquele que é mais } \\
\text { importante, no entanto acessou um blog e disse que era confiável. Precisou de ajuda } \\
\text { para copiar e colar o arquivo no Word (2). }\end{array}$ \\
\hline
\end{tabular}

Fonte: Elaboração própria.

Sobre a temática da pesquisa realizada nessa atividade, observa-se que a maioria dos estudantes optou por temáticas ligadas aos seus interesses ou a conteúdos escolares que estavam sendo aprendidos na escola.

A respeito da escolha da palavra-chave, na pesquisa, nota-se que os estudantes a usaram de maneira convencional, sendo que alguns apelaram a perguntas como, por exemplo: “Quais são as características do período neolítico e paleolítico?”. Costa (2002) aponta que quando a seleção da palavra-chave não é adequada é possível se correr o risco 
de obter um número excessivo ou reduzido de resultados, ao passo que, se adotarmos palavras-chave mais sintéticas, obteremos resultados mais precisos.

Com base na classificação de Monereo (2010), considera-se que os estudantes que utilizaram a Wikipédia e o Yahoo Respostas como fonte de busca ainda se encontravam em um estágio de buscador ativo, enquanto aqueles que empregaram estratégias de pesquisa mais elaboradas se mostraram como seletivos, preocupando-se com o objetivo da pesquisa e a fonte de informação a ser acessada.

Quadro 4 - Atividade: Jogos Online

\begin{tabular}{|l|l|}
\hline \multicolumn{2}{|c|}{ Atividade - Jogos Online } \\
\hline $\begin{array}{l}\text { Maria } \\
\text { Fernanda }\end{array}$ & $\begin{array}{l}\text { Acessou o site de jogos Iguinho, fez uma exploração dos jogos por meio da tentativa e } \\
\text { erro. Observou-se que a aluna realizou uma exploração intuitiva dos jogos (2). }\end{array}$ \\
\hline Gustavo & $\begin{array}{l}\text { Acessou o site de jogos Iguinho, fez uma exploração dos jogos por meio da tentativa e } \\
\text { erro. Relatou que explora os jogos por meio da tentativa e erro, não gosta de ver tutoriais } \\
\text { e nem vídeos sobre eles (2). }\end{array}$ \\
\hline Vitor & $\begin{array}{l}\text { Acessou o site Friv. Se há instruções explícitas o estudante segue as orientações, se não } \\
\text { há, explora os jogos de modo intuitivo (2). }\end{array}$ \\
\hline Eduarda & $\begin{array}{l}\text { Acessou os sites "Mafa" e "Papa Jogos", relatou explorar os jogos aleatoriamente até } \\
\text { conseguir jogar corretamente (2). }\end{array}$ \\
\hline Alice & $\begin{array}{l}\text { Acessou o site Friv. Explorou os jogos por meio da tentativa e erro até conseguir jogar } \\
\text { corretamente (2). }\end{array}$ \\
\hline Luís & Acessou o Click Jogos, explorou os jogos de modo aleatório até conseguir acertar (2). \\
\hline
\end{tabular}

Fonte: Elaboração própria.

Identifica-se que a interatividade proporcionada pelos jogos, a empolgação provocada por eles e a segurança que os nativos digitais sentem na internet favorecem o sentimento de confiança em explorar um jogo sem conhecer as regras, mesmo porque o fazem livremente e realizam quantas tentativas forem necessárias para aprender a jogar corretamente. Considera-se que essa conduta prejudica o aproveitamento do jogo, visto que estes desenvolvem habilidades variadas e estimulam o raciocínio e, quando jogados com intencionalidade, podem desafiar mais o usuário. Sobre a utilização de jogos digitais por estudantes superdotados, Shamblin (2011) afirma que eles são excelentes recursos pedagógicos, quando são desafiadores e envolventes. Hung et al. (2012) complementam essa afirmação ao destacarem que o uso das TDIC no contexto educativo sem objetivos e estratégias eficazes pode ser decepcionante, enfatizando a importância de uma escolha assertiva dos recursos tecnológicos. 
Observa-se que, embora todos os jogos contivessem instruções, em alguns casos estas não foram suficientes para que o estudante compreendesse seu objetivo, reforçando a importância da mediação e da intencionalidade (ANSELL, 2016).

Para Mendonça (2018), os jogos online fazem parte da cultura digital, de modo que a utilização deles em sala de aula valoriza o conhecimento e a vivência dos estudantes, propiciando uma utilização participativa e crítica desses recursos digitais.

\section{Quadro 5 - Atividade: Redes Sociais}

\begin{tabular}{|l|l|}
\hline \multicolumn{2}{|c|}{ Atividade - Redes Sociais } \\
\hline $\begin{array}{l}\text { Maria } \\
\text { Fernanda }\end{array}$ & Não realizou a atividade (1). \\
\hline Gustavo & Não tem mais conta no Facebook, no entanto sabe utilizar os recursos (3). \\
\hline Vitor & Não realizou a atividade (1). \\
\hline Eduarda & $\begin{array}{l}\text { Utilizava as redes sociais, relatou cuidado com as pessoas que adiciona e que acessam } \\
\text { seus conteúdos. (3). }\end{array}$ \\
\hline Alice & $\begin{array}{l}\text { Apresentou domínio da utilização, todavia não altera as configurações de privacidade } \\
\text { (3). }\end{array}$ \\
\hline Luís & $\begin{array}{l}\text { Apresentou domínio na utilização, contudo não altera as configurações de privacidade } \\
(3) .\end{array}$ \\
\hline
\end{tabular}

Fonte: Elaboração própria.

Durante as atividades, aqueles que possuíam contas no Facebook relataram que geralmente adicionavam apenas pessoas conhecidas, como amigos e parentes. Estes não alteravam as configurações de privacidade, de forma que o perfil e as postagens ficavam visíveis para qualquer pessoa.

Barbovski (2015) sustenta que o alto índice de crianças e adolescentes nas redes sociais representa maior vulnerabilidade entre esses jovens, sendo que pais e professores devem estar atentos a possíveis agressões virtuais e uso indevido dos dados pessoais. Os achados de pesquisa desse autor apontam que há uma relação entre as habilidades digitais e as estratégias de enfrentamento usadas pelos usuários ao se depararem com ações abusivas na internet.

Sobre os perigos da superexposição de crianças e adolescentes nas redes sociais, Pereira e Teza (2015) destacam que seu emprego pelos menores de idade impulsiona crimes como a pedofilia virtual, pois, muitas vezes, estes usam esses recursos sem limite e orientação, tornando-se alvos vulneráveis para criminosos. 
A segurança é um dos itens apontados por Lueg (2014) como importante no contexto das competências digitais porque os usuários devem proteger os dados pessoais na internet e fazer uso seguro dela. A respeito dessa exposição da vida privada nas redes sociais, Dalbosco (2015) aponta que vivemos uma banalização da intimidade e da individualidade, fatos esses que precisam ser discutidos com os nativos digitais para que tenham responsabilidade sobre as postagens que efetuam e seu efeito (positivo ou negativo) em suas vidas.

\section{Tecnologias Digitais da Informação e Comunicação: conhecimento dos professores}

Indagou-se aos professores se eles haviam recebido formação específica para utilizar as TDIC no contexto escolar, três professores indicaram que não receberam nenhuma formação, dois afirmaram que obtiveram conhecimentos por meio de cursos de pós-graduação e um afirmou que aprendeu de modo autodidata e por meio de oficinas. De acordo com os dados da pesquisa TIC Educação (2015), metade dos professores entrevistados (cerca de 890 professores) afirmou que falta preparação para a utilização das TDIC enquanto recursos pedagógicos. O déficit de formação na área tecnológica não acontece apenas no âmbito da formação inicial, sendo que os cursos de formação continuada e pós-graduação nem sempre ofertam tal formação de modo satisfatório (THADEI, 2018).

Ao serem indagados sobre a frequência com que utilizavam os recursos tecnológicos em sala de aula, dois professores afirmaram que utilizavam semanalmente, dois mensalmente e um afirmou utilizar sem uma frequência estabelecida. A baixa frequência de utilização das TDIC pode ser atribuída à formação deficitárias dos professores sobre como integrar tais recursos nas práticas pedagógicas, como também pode estar associada à falta de equipamentos e infraestrutura para sua utilização. Segundo Barros e Brighenti (2004), as instituições que ofertam cursos de formação de professores devem inserir os futuros profissionais em situações reais do cotidiano escolar, por meio do conhecimento científico e tecnológico contemporâneo.

Sobre os recursos tecnológicos comumente utilizados em sala de aula, verificouse que filme, vídeo, sites e apresentação de slides foram os mais citados. Apenas três 
professores afirmaram utilizar softwares e jogos educativos, sendo que um único participante afirmou não utilizar qualquer recurso tecnológico em sua prática educativa.

Ao analisar os recursos tecnológicos mais utilizados pelos professores, observase que ainda há uma subutilização das TDIC disponíveis de modo gratuito. Os recursos tecnológicos mais utilizados pelos professores não favorecem uma participação ativa do estudante no processo de ensino-aprendizagem, sendo que esses apenas apresentam informações aos estudantes. Atualmente há inúmeros recursos tecnológicos que colocam os estudantes em ação e no centro do processo educativo, ferramentas como Powtoon, Google Forms e Goconqr possibilitam a produção de conteúdo e exploram a criatividade dos alunos (PEDRO, 2018).

Em relação à finalidade com que os recursos tecnológicos são utilizados no cotidiano escolar, verifica-se as seguintes respostas: para exibição de filmes e vídeos (6), para produzir atividades e materiais (5), como ferramenta de pesquisa (4) e para utilização de jogos e softwares educativos (2). Observou-se que os professores participantes reconhecem o potencial das TDIC para produção de atividades e materiais didáticos, como também para enriquecer as aulas por meio de filmes e vídeos, no entanto a utilização de jogos, softwares e realização de pesquisas ainda se dá de modo insuficiente.

A Base Nacional Curricular Comum (BNCC) reafirma a necessidade de promover uma utilização crítica, significativa, reflexiva e ética das tecnologias, sendo necessário considerar as TDIC não apenas como recursos pedagógicos, mas como itens preponderantes para a formação social, ética e estética do ser. Nessa perspectiva, Vickery (2016, p. 53) afirma que o professor desempenha um papel fundamental em ensinar as crianças a utilizarem as TDIC com sabedoria. "As crianças devem ser ajudadas a reconhecer e compreender o viés potencial e as implicações morais trazidas pela tecnologia".

A respeito das facilidades e dificuldades para a integração dos recursos tecnológicos ao currículo escolar, quatro professores afirmaram haver mais facilidades, enquanto dois admitiram encontrar mais dificuldades. Sobre as facilidades, os professores destacaram: que ao considerar a geração dos nativos digitais, o trabalho com recursos tecnológicos fica mais interessante para os estudantes, sendo possível enriquecer a aula de diversas maneiras; a grande maioria dos estudantes está inserida no mundo virtual, de modo que eles próprios trazem materiais e assuntos vinculados na internet para discussão 
em sala de aula, sendo visível o modo como os conteúdos são assimilados de forma prazerosa por meio das TDIC; desperta o interesse dos alunos, facilita a compreensão do conteúdo e a interatividade.

Em relação aos aspectos que dificultam a utilização das TDIC no contexto escolar, os professores destacaram problemas na infraestrutura, ambientes inadequados, número de equipamentos insuficientes e falta de formação específica. Nos últimos anos tivemos várias iniciativas de inserção das TDIC nos ambientes escolares, o Programa um Computador por Aluno (PROUCA) e o Programa Nacional de Tecnologia Educacional (PROINFO) foram algumas delas, no entanto, essas ainda não foram suficientes para equipar as escolas adequadamente.

Sobre o conhecimento dos professores relativo às metodologias inovadoras e ativas de ensino, verificou-se que a aprendizagem baseada em problemas, sala de aula invertida e ensino híbrido são as propostas metodológicas mais conhecidas pelos professores, visto que apenas um indicou conhecer a proposta relacionada à robótica. Inúmeros autores indicam que a adoção das metodologias ativas nas práticas escolares configura-se como uma excelente estratégia para envolver os estudantes nas atividades escolares (VALENTE, 2015; THADEI, 2018). Para Vickery (2016) a escola do século XXI precisa desenvolver uma aprendizagem epistêmica, a qual deve se concentrar em desenvolver estudantes críticos, focados no aprender, pensar e saber.

Em relação à experiência dos professores com as abordagens metodológicas citadas acima, observou-se que a sala de aula invertida é praticada por dois professores, esses estimulam seus alunos a realizarem pesquisas e leituras prévias, de modo que eles estejam mais bem preparados e mais engajados no momento da aula. Nessa metodologia, o professor deve selecionar os recursos que serão disponibilizados previamente, planejar as atividades que serão realizadas no momento presencial, receber e esclarecer as dúvidas dos estudantes. Assim, as informações básicas sobre um determinado conteúdo ficam disponíveis de modo online e o aprofundamento do tema acontece em sala de aula.

Segundo Valente (2015), a proposta da sala de aula invertida é extremamente favorável, pois estamos em um momento de intensa ascensão das TDIC, em que os estudantes nascidos na era digital usam esses recursos como extensões do próprio corpo, embora nem sempre essa utilização esteja pautada em uma perspectiva produtiva e de aprendizagem. 
Em relação aos recursos tecnológicos que os professores utilizavam com os estudantes identificados como $\mathrm{AH} / \mathrm{SD}$, um professor afirmou incentivar a pesquisa de conteúdos na internet, enquanto outro afirmou que não aplica nenhuma atividade diferenciada, sendo que todos os alunos da classe devem realizar as mesmas atividades. Os demais professores não responderam essa questão, uma vez que indicaram não utilizar nenhum recurso tecnológico com esse alunado.

Ressalta-se que os recursos tecnológicos devem ser utilizados com todos os estudantes, de modo que o princípio de uma educação equitativa seja sempre respeitado. Quando se considera, especificamente, a educação de estudantes com AH/SD, há que se ponderar que o processo de ensino-aprendizagem desses estudantes pode ser favorecido e enriquecido por meio das TDIC. De acordo com Bacich (2018), devemos organizar a escola de maneira que possamos aproveitar o melhor dos dois âmbitos: o presencial e o online, explorando ao máximo os recursos tecnológicos disponíveis.

Por fim, os professores foram indagados se eles acreditavam que as TDIC poderiam ser consideradas ferramentas de enriquecimento, quatro responderam afirmativamente e dois deles destacaram os seguintes pontos:

\footnotetext{
Usar as tecnologias é atender a necessidade da sociedade contemporânea e a escola precisa caminhar nessa direção, pois ao contrário é continuar em um modelo de escola que está ultrapassado. É possível oferecer muito enriquecimento e a partir do momento que se ensina usar essas ferramentas e de maneira adequada, os alunos começam a ter autonomia para tornarem-se cada vez mais produtores de conhecimentos. Além disso, é mais inclusivo, oferece um processo de ensino e aprendizagem mais rico, atendendo também os alunos que têm dificuldade para aprender com metodologia tradicional (P1).

Fazer uso de jogos, vídeos, softwares, pesquisas em sites em geral se faz necessário; considerando que suas características, interesses, ritmo de aprendizagem são diferenciados, é necessário, também, um planejamento de estratégias e atividades também diferenciadas que poderão auxiliá-los a se aprofundarem em conteúdos e temas e, a pesquisarem de acordo com a área de interesse que é tão abrangente (P4).
}

Ao analisar os relatos dos professores, verificou-se que, embora haja elementos de infraestrutura e de formação que dificultam o trabalho docente com as TDIC, esses reconhecem e valorizam o potencial desses recursos no âmbito da educação de estudantes superdotados. Desse modo, acredita-se na necessidade de oferta de cursos de formação continuada e em serviço que atenda as demandas cotidianas dos professores. Segundo Bacich (2018, p. 150), as propostas de formação de professores são ineficientes quando 
desconsideram "a lacuna entre o que os professores estudam e o contexto em que esse conhecimento será aplicado".

\section{Considerações Finais}

Ao término deste artigo, percebe-se que embora a cultura digital seja uma realidade dentro e fora das escolas, ainda há muito que avançar no que se refere às competências digitais de professores e alunos, no uso dos recursos tecnológicos.

A análise do desempenho dos estudantes nas atividades propostas revela que embora eles sejam considerados nativos digitais e apresentem habilidades no manuseio e acesso de alguns aplicativos, há a necessidade de aperfeiçoar o modo como eles realizam

pesquisas e utilizam ferramentas de produção. É perceptível que esses estudantes fazem uma utilização pautada principalmente na "tentativa e erro", o que não promove uma utilização intencional e assertiva das TDIC.

Nesse sentido, faz-se necessário ofertar aos estudantes atividades pedagógicas, por meio das tecnologias digitais, que tenham por objetivo muito mais do que a instrumentalização, mas que possibilitem ao estudante a utilização de ferramentas de produção de conteúdo e a avaliação crítica das informações disponíveis na internet.

As TDIC, quando usadas com intencionalidade e de modo produtivo, podem configurar-se como ferramentas de enriquecimento, uma vez que possibilitam o acesso a qualquer tipo de informação e mídia, além da produção de conteúdos interativos e dinâmicos. Os estudantes participantes da pesquisa reconheceram o potencial educacional das TDIC e podem aperfeiçoar essa utilização por meio de atividades mediadas e do desenvolvimento das competências digitais.

Sobre o conhecimento dos professores em relação às TDIC, verificou-se que ainda há uma subutilização dos recursos tecnológicos no âmbito escolar, visto que os professores exploram com mais frequência recursos como vídeos e filmes em detrimento dos recursos que possibilitam maior interação e produção de conteúdos. Tal subutilização pode ser atribuída à infraestrutura deficitária das instituições escolares, no âmbito tecnológico, como também às lacunas no campo da formação de professores. 


\section{Referências}

ANSELL, K. Aprendizagens ativas com as TICs. In: VICKERY, A. et al. Aprendizagem ativa nos anos iniciais do ensino fundamental. Porto Alegre: Penso, 2016. p. 127-146.

BACICH. L. Formação continuada de professores para o uso das metodologias ativas. In: BACICH, L.; NETO, A. T.; TREVISANI, F. M. (Orgs.) Ensino Híbrido: personalização e tecnologia na educação. Porto Alegre: Penso, 2015. p. 129-152.

BARBOVSKI, M. Habilidades técnicas e o enfrentamento do uso abusivo de dados pessoais e agressão entre pares em redes sociais. In: BARBOSA, A. F. (Coord.). Pesquisa sobre o uso da internet por crianças e adolescentes no Brasil: TIC Kids Online Brasil 2014. São Paulo: Comitê Gestor da Internet no Brasil, 2015. p. 181-186.

BARROS, D. M. V.; BRIGHENTI, M. J. L. Tecnologias da informação e comunicação \& formação de professores: tecendo algumas redes de conexão. In: RIVERO, C. M. L.; GALLO, S. (Org.) A formação de professores na sociedade do conhecimento. Bauru: Edusc, 2004. p. 125-144.

BRASIL. Ministério da Educação. Base Nacional Comum Curricular - BNCC. Brasília: DF, 2017.

COMITÊ GESTOR DA INTERNET NO BRASIL. Pesquisa sobre o uso da internet por crianças e adolescentes no Brasil - TIC Kids Online Brasil 2014. São Paulo: CGI.br, 2015. Disponível em: http://www.cetic.br/publicacoes/indice/page:2. Acesso em: 04 fev. 2016.

COSTA, R. A cultura digital. São Paulo: Publifolha, 2002.

DALBOSCO, C. A. Formação humana na sociedade digital. In: MAIA, A. F.; ZUIN, A. A. S.; LASTÓRIA. L. A. C. N. (Org.). Teoria crítica da cultura digital. São Paulo: Nankin, 2015, p. 11-26.

FREITAS, S. N.; PÉREZ, S. G. P. B. Altas Habilidades/Superdotação: atendimento especializado. Marília: ABPEE, 2010.

HUNG, P.; HWANG, G.; SU, I.; LIN, I. A Concept-Map Integrated Dynamic Assessment System for Improving Ecology Observation Competences in Mobile Learning Activities. Turkish Online Journal of Educational Technology - TOJET, v. 11, n. 1, p. 10-19. 2012. Disponível em: http://files.eric.ed.gov/fulltext/EJ976563.pdf. Acesso em: 29 dez. 2015.

ILLERA, J. L. R.; ROIG, A. E. Ensino e aprendizagem de competência comunicacionais em ambientes virtuais. In: COLL, C.; MONEREO, C. (Org.). Psicologia da Educação Virtual: aprender e ensinar com as Tecnologias da Informação e da Comunicação. Porto Alegre: Artmed, 2010. p. 329-345. 
LUEG, C. F. Competencia digital docente: desempeños didácticos en la formación incial del profesorado. Revista Científica de Educación y Comunicación. Educom: CádizEspanha, nov., 2014, p. 55-71.

MENDONÇA, H. A. Construção de jogos e uso de realidade aumentada em espaços de criação digital na educação básica. In: BACICH, L.; MORAN, J. (Org.) Metodologias ativas para uma educação inovadora: uma abordagem teórico-prática. Porto Alegre: Editora Penso, 2018, p. 106-128.

MONEREO, C.; AGUSTÍ, M. F. Aprender a buscar y seleccionar en Internet. In: MONEREO, C. (Coord.). Internet y competencias básicas: aprender a colaborar, a comunicarse, a participar, a aprender. Barcelona: Editora GRAÓ, 2010. p. 27-50.

PALFREY, J; GASSER, U. Nascidos na era digital: entendendo a primeira geração dos nativos digitais. Porto Alegre: Artmed, 2011.

PEDRO, K. M. Estudo comparativo entre nativos digitais sem e com precocidade e comportamento dotado. (Doutorado em Educação) - Faculdade de Filosofia e Ciências, Unesp/Marília, 2016. Disponível em: http://repositorio.unesp.br/handle/11449/143469. Acesso em: 01 set. 2016.

PEDRO, K. M. Superdotação, tecnologias e metodologias ativas: perspectivas educacionais contemporâneas. In: RANGNI, R. A. (Org.) Altas habilidades: sugestões para pesquisadores e educadores. São Carlos: EduFSCar, 2019. p. 203-218.

PEREIRA, A. S. H.; TEZA, A. A pedofilia virtual: como conferir proteção integral aos direitos de crianças e adolescentes na rede? In: XII Seminário Internacional de Demandas Sociais e Políticas Públicas na Sociedade Contemporânea e VIII Mostra de Trabalhos Jurídicos Científicos. Anais. 2015.2 Disponível em: https://online.unisc.br/acadnet/anais/index.php/sidspp/article/viewFile/13164/2360. Acesso em: 05 jun. 2016.

RENZULLI, J. S. A concepção de superdotação no modelo dos três anéis: Um modelo de desenvolvimento para a promoção da produtividade criativa. In: VIRGOLIM, A. M. R.; KONKIEWITZ, E. C. (Org.). Altas Habilidades/Superdotação, inteligência e criatividade. Campinas: Editora Papirus, 2014. p. 219-264.

RIVERO, C. M. L. O cenário educacional: o professor e sua prática docente diante das mudanças atuais. In: RIVERO, C. M. L.; GALLO, S. (Org.) A formação de professores na sociedade do conhecimento. Bauru: Edusc, 2004. p. 79-100.

SANTAELLA, L. A aprendizagem ubíqua na educação aberta. Revista Tempos e Espaços em Educação, v. 7, n. 14, p. 15-22, 2014. Disponível em: http://www.seer.ufs.br/index.php/revtee/article/view/3446. Acesso em: 18 jan. 2017.

SHAMBLIN, M. Computer technology for the gifted and talented child! Focused investigation paper with research and personal experiences in educating students with computer technology. 2011. Disponível em: http://mrshamblin.pbworks.com/f/ShamblinMichaelFocusedInvestigationPDF.pdf. Acesso em: 06 jun. 2016. 
THADEI, J. Mediação e educação na atualidade: um diálogo com formadores de professores. In: BACICH, L.; MORAN, J. (Org.) Metodologias ativas para uma educação inovadora: uma abordagem teórico-prática. Porto Alegre: Editora Penso, 2018. p. 90-105.

VALENTE, J. A. Prefácio. In: BACICH, L.; NETO, A. T.; TREVISANI, F. M. (Orgs.) Ensino Híbrido: personalização e tecnologia na educação. Porto Alegre: Penso, 2015. p. 13-20.

VICKERY, A. Criando uma cultura da indagação. In: VICKERY, A. et al. Aprendizagem ativa nos anos iniciais do ensino fundamental. Porto Alegre: Penso, 2016. p. 43-66.

Recebido em: 16 set. 2019.

Aceito em: 17 mar. 2020. 